\title{
Impact of a Water Intervention on Sugar-Sweetened Beverage Intake Substitution by Water: A Clinical Trial in Overweight and Obese Mexican Women
}

\author{
Sonia Hernández-Cordero ${ }^{a}$ Barry M. Popkin ${ }^{b}$ \\ aCenter of Research in Nutrition and Health, National Institute of Public Health, Mexico City, Mexico; \\ ${ }^{b}$ Carolina Population Center, University of North Carolina at Chapel Hill, Chapel Hill, N.C., USA
}

\section{Key Words}

Water · Sugar-sweetened beverages · Interventions

\begin{abstract}
Background/Aims: Intense marketing for sugar-sweetened beverages (SSB) along with the human innate preference for sweet taste contributes to the increase in consumption of SSB. It is important to understand the intricacies of dietary intake and global changes to the food supply to understand the complexities facing any intervention promoting water intake. We describe challenges to promote and achieve an increase in water intake and present key findings from a clinical trial examining the effects of substituting water for SSB on triglyceride levels, weight and other cardiometabolic factors in overweight/obese Mexican women. Methods: A randomized trial was conducted in Cuernavaca, Mexico selecting overweight/obese (BMI $\geq 25$ and $<39 \mathrm{~kg} / \mathrm{m}^{2}$ ) women (1845 years old), reporting an intake of SSB of at least $250 \mathrm{kcal} /$ day. Women were randomly allocated to the water and education provision (WEP) group $(n=120)$ or to the education provision (EP) group $(n=120)$. Repeated $24 \mathrm{~h}$ dietary recall questionnaires, anthropometry, and fasting blood levels were collected at baseline and 3, 6, and 9 months following the intervention. Results: There was no effect of the intervention on triglyceride concentration or on any of the stud-
\end{abstract}

ied outcomes. Post-hoc analyses according to weight at baseline show that triglyceride concentration decreased in obese women. Prevalence of metabolic syndrome after the intervention was lower in obese women from the WEP group. Conclusion: Water intake was increased but insufficient to achieve complete substitution of SSB, without effects on triglyceride concentration. Post-hoc analyses suggested that interventions lowered triglyceride concentration. Further studies are needed.

(c) 2015 S. Karger AG, Basel

\section{Introduction}

Evidence shows that sugar-sweetened beverages (SSB) are the largest source of added sugar in most regions of the world. Its consumption is linked with long-term weight gain, risk of type 2 diabetes, metabolic syndrome and cardiovascular disease [1-3]. Evidence, albeit limited, shows that water intake - when replacing SSB, juice and milk - is linked with reduced energy intake [4]. Intense marketing for SSB along with the innate human preference for sweet taste $[5,6]$ are some of the factors that contribute to the increase in SSB consumption in most countries [7-9]. This report describes the challenges that exist to promote and achieve an increase in water intake

\begin{tabular}{ll}
\hline KARGER 125.s. & $\begin{array}{l}\text { ( ) 2015 S. Karger AG, Basel } \\
0250-6807 / 15 / 0667-0022 \$ 39.50 / 0 \quad \text { Karger }\end{array}$ \\
$\begin{array}{l}\text { E-Mail karger@karger.com } \\
\text { www.karger.com/anm }\end{array}$ & $\begin{array}{l}\text { This is an Open Access article licensed under the terms of the } \\
\text { Creative Commons Attribution-NonCommercial 3.0 Un- } \\
\text { ported license (CC BY-NC) (www.karger.com/OA-license), } \\
\text { applicable to the online version of the article only. Distribu- } \\
\text { tion permitted for non-commercial purposes only. }\end{array}$
\end{tabular}

Sonia Hernández-Cordero

Center of Research in Nutrition and Health, National Institute of Public Health Séptima Cerrada de Fray Pedro de Gante N. 50

Col. Sección XVI, CP 14080, México City (Mexico)

E-Mail cordero@insp.mx 
as well as elucidates some key findings of a clinical trial in overweight and obese Mexican women aimed at examining the effect of substituting SSB with water on an array of cardiometabolic factors.

\section{Challenges to Promote and Achieve an Increase in Water Intake}

Throughout history, sweetness preference was essential for the survival and evolution for human kind [10]. As the modern manufacturing and food distribution systems and consumer packaged goods (CPG) have evolved along with modern marketing and global subsidies of sugar [11], modern beverage companies have used the preferences of sweetness to create inexpensive beverage alternatives to water and to increase intake of high-caloric sweetened beverages and foods. More recently, promotions of products have been expanded to cover nonnutritive sweetened foods and beverages [12]. In addition, fresh-food markets are disappearing, being replaced by convenience stores and supermarkets in low- and middle-income countries, resulting in processed, packaged foods/beverages rapidly reaching the entire population [13]. In Mexico, $53 \%$ of kilocalories per capita and $30 \%$ of calories in China come from processed or packaged foods/beverages [14]. In this context, water intake in its natural form is displaced by less healthful options. Thus, when retailers and the CPG sectors expanded globally, dietary worldwide patterns shifted. Over the past decades, there has been an increase in the intake of SSB worldwide. Global SSB intake has grown rapidly as has sugar from processed foods $[15,16]$. In Mexico, consumption of caloric beverages doubled from 1999-2006 and by the year 2012, SSB were among the most consumed beverages $[9$, 17].

It is important to understand the complexity of the dietary intake and global changes in the food supply to understand the complexities facing any intervention to promote water intake among adults and adolescents. The resultant beverage consumption patterns have increasingly replaced water with sweetened and/or caffeinated beverages. Current research is attempting to develop methods to promote water intake. An increasing number of studies involving children show that limited periods of intense interventions can replace other beverages. The first largescale study was done in German schools, showing that replacing vending machines and beverage choices with filtered water fountains plus water education, reduced risk of overweight by $31 \%$ [18].

Impact of Water Interventions and

Sugar-Sweetened Beverages
To date, evidence shows that the best option for the successful promotion of water intake is to improving drinking water access along with health education about the importance of drinking more water (and decreasing SSB) and targeting early stages of life (children) or highrisk populations (i.e., overweight and obese individuals) [19-21]. As far as the knowledge of the authors go, no similar research has been conducted successfully with adults with a sole focus on water. While most weight-control interventions promote water use, few evaluate the impact on water use aside from one weight control randomized controlled trial that focused on provision of water or diet beverages [22].

\section{Results of a Randomized Trial in Overweight and Obese Mexican Women}

We conducted a randomized trial in Mexico, a country with one of the highest rates of consumption of SSB globally [9] and with 73\% of women being overweight and obese [23]. The methods and results were published elsewhere $[24,25]$. Briefly, the trial was conducted in Cuernavaca, México, examining the effect of substituting SSB with water on plasma triglycerides (TG) (primary outcome), weight, and other cardiometabolic factors, as well as evaluating how an increase in water intake affects dietary intake quality. We selected overweight/obese (BMI $\geq 25$ and $<39 \mathrm{~kg} / \mathrm{m}^{2}$ ) women ( $18-45$ years old) reporting SSB intake of at least $250 \mathrm{kcal} /$ day. Women were randomly allocated to the water and education provision (WEP) group $(n=120)$ or the education provision (EP) only group $(n=120)$. The WEP group received biweekly water deliveries and both groups received equal monthly nutrition counseling. During nutrition counseling, the WEP group sessions included activities to encourage increased water intake, reduced SSB intake, and substitution of water for SSB. Repeated $24 \mathrm{~h}$ dietary recall questionnaires, anthropometry, and fasting blood were collected at baseline and at 3,6, and 9 months following the intervention [24]. Multiple imputations using the Markov-Monte Carlo method were used. Separate mixed-effect models tested each outcome in the intent-to-treat analysis (ITT). Post-hoc analyses were done considering the nutritional status (measured as BMI) at baseline and increase in water intake during the intervention [25].

\section{Results}

ITT analyses showed no effect of the intervention on TG concentration or other studied outcomes despite increased reported water intake and reduced SSB intake. Some potential explanations for these results are incomplete replacement of SSB consumption reported by participants, women in the WEP group still had a high consumption ( $155 \mathrm{kcal} \pm 4 \mathrm{kcal} /$ day or $418 \mathrm{ml} /$ day), women in the EP group decreased consumption of SSB and a 


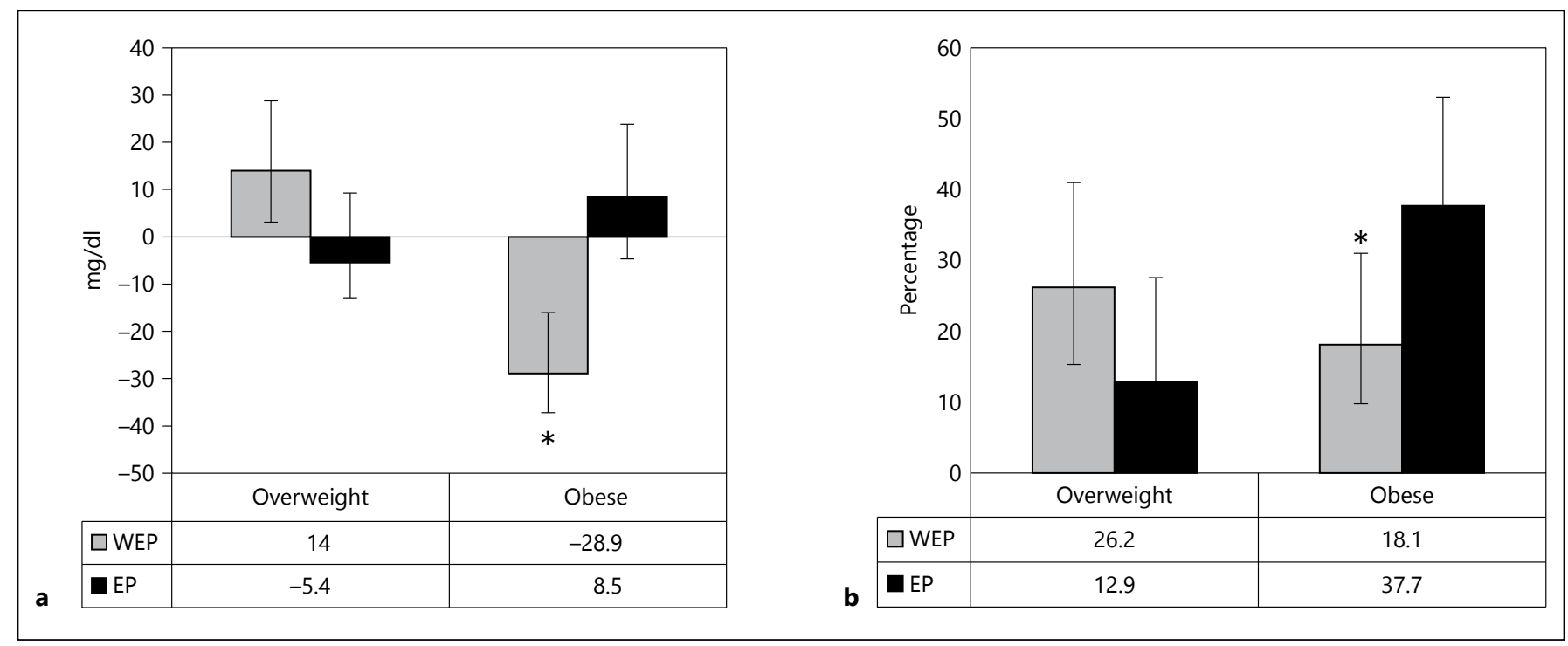

Fig. 1. Effects of the intervention at 9 months based on baseline weight status. (Post-hoc analyses) (a) Plasma triglyceride change from baseline to 9 months. b Prevalence of metabolic syndrome at 9 months. Values presented are mean \pm SE for (a) and percentages and $95 \%$ CI for (b). a Simple linear regression model of the change in plasma triglycerides from baseline to 9 months on the treatment group $(\mathrm{WEP}=1, \mathrm{EP}=0$ ) and $\mathrm{BMI}$ at baseline (obese $=1$, over-

considerable percentage (37\%) increased water intake to $>1.2 \mathrm{l} /$ day. Finally, women in both groups decreased total energy intake during the study.

In the post hoc analyses, considering that weight status interacted with the treatment (obesity or BMI $\geq 30$ vs overweight or BMI $\geq 25$ and $<30$ ) at baseline, we found that TG concentration decreased from baseline to 9 months in the obese WEP group (228.9-67.70 mg/dl; $p$ value for change $<0.001)$ with no change in the EP group $(8.50-10.9 \mathrm{mg} / \mathrm{dl} ; \mathrm{p}$ value for change $=0.4)$. The prevalence of metabolic syndrome at the end of the intervention was significantly lower for obese women in the WEP group (figure 1) [25]. Some potential explanations for these results are a greater physiological response in subjects with greater risk (obese women) and better compliance to the intervention by obese women. In our study, women in the WEP group demonstrated greater water intake and a greater decrease in the consumption of SSB.

Finally, when we considered the increase in water intake during the intervention, we found that women with a greater increase in water intake showed a higher weight loss, adjusting for age, physical activity (in METs/day), energy intake from solids and from SSB. Thus for every additional liter of water intake during the intervention, women lost $0.4 \pm 0.1 \mathrm{~kg}, \mathrm{p}>0.005$. weight $=0)$; Interaction term: Treatment $*$ BMI at baseline; $(\mathrm{n}=$ 184). b Logistic regression model adjusted by prevalence of MetS at baseline, treatment $(\mathrm{WEP}=1, \mathrm{EP}=0), \mathrm{BMI}$ at baseline (obese $=$ 1 , overweight $=0$ ), change in physical activity from baseline to 9 months, age at baseline, interaction treatment. ${ }^{*} \mathrm{BMI}$ at baseline; $(\mathrm{n}=179) .{ }^{*}$ WEP different from EP, $\mathrm{p}<0.05$. EP = Education provision, $\mathrm{WEP}=$ water and education provision.

\section{Conclusions}

The intervention resulted in increased water intake but was insufficient to achieve a complete substitution of SSB. There was no effect on TG concentration or other cardiometabolic outcomes. Secondary analysis suggests that water intervention lowered TG concentration and prevalence of metabolic syndrome among obese women. This represents an important finding considering that, in Mexico, 37.5\% of women are obese [23]. In addition, we found that increased water intake was associated with lower carbohydrate intake and greater weight loss. Results of ITT and secondary analyses require further studies.

\section{Disclosure Statement}

No authors have consulted with the Danone Research Center, but some have had grants to conduct epidemiological analyses/talk at Brit Nutr Soc on beverage patterns (BP) or partial support for sabbatical research at the University of North Carolina at Chapel Hill (SHC). 


\section{References}

1 Malik V, Popkin BM, Bray GA, Deprés JP, Hu FB: Sugar-sweetened beverages, obesity, type 2 diabetes and cardiovascular disease risk. Circulation 2010;121:1356-1364.

-2 Malik V, Pan A, Willet W, Hu FB: Sugarsweetened beverages and weight gain in children and adults: a systematic review and meta-analysis. Am J Clin Nutr 2013;98:10841102.

3 Hu FB: Resolved: there is sufficient scientific evidence that decreasing sugar-sweetened beverage consumption will reduce the prevalence of obesity and obesity-related diseases. Obes Rev 2013;14:606-619.

4 Daniels MC, Popkin BM: The impact of water intake on energy intake and weight status. Nut Rev 2010;68:505-521.

$>5$ Yngve A, Haapala I, Hodge A, McNeill G, Tseng M: Making soft drinks the dietary version of the cigarette. Public Health Nutr 2012; 15:1329-1330.

$>6$ Ventura AK, Menella JA: Innate and learned preferences for sweet taste during childhood. Curr Opin Clin Nutr 2011;14:379-384.

$>7$ Popkin BM: Patterns of beverage use across the life cycle. Physiol Behav 2010;100:4-9.

$>8$ Ratnayake N, Ekanyala L: Soft drink consumption in Sri Lankan adolescents. Public Health Nutr 2012;15:1333-1337.

$>9$ Stern D, Piernas C, Barquera S, Rivera JA, Popkin BM: Caloric beverages were major sources of energy among children and adults in Mexico, 1999-2012. J Nutr 2014;144:949956.

10 Popkin BM: The World is Fat-The Fads, Trends, Policies, and Products that are Fattening the Human Race. New York: Avery Penguin Group, 2008.

11 Popkin BM, Nielsen SJ: The sweetening of the world's diet. Obes Res 2003;11:1325-1332.
12 Ng S, Slining MM, Popkin BM: Use of caloric and noncaloric sweeteners in US consumer packaged foods, 2005-2009. J Acad Nutr Diet 2012;112:1828-1834.e1-e6.

13 Reardon T, Timmer CP, Barrett CB, Berdegue JAC: The rise of supermarkets in Africa, Asia, and Latin America. Am J Agric Econ 2003;85: 1140-1146.

14 Popkin BM: Nutrition, agriculture and the global food system in low and middle income countries. Food Policy 2014;47:91-96.

15 Kleiman NS, Popkin B: Drinking to our health: can beverage companies cut calories while maintaining profits? Obes Rev 2011;13: 258-274.

16 Moubarac M, Cannon G, Ng SW, Popkin B: Ultra-processed products are becoming dominant in the global food system. Obes Rev 2013;14:21-28.

-17 Barquera S, Hernández L, Tolentino ML, Espinosa J, Leroy J, Rivera J, Popkin BM: Energy from beverages is on the rise among Mexican adolescents and adults. J Nutr 2008;138: 2454-2461.

18 Muckelbauer R, Libuda L, Clausen K, Toschke AM, Reinehr T, Kersting M: Promotion and provision of drinking water in schools for overweight prevention: randomized, controlled cluster trial. Pediatrics 2009;123: e661-e667.

19 Patel AI, Bogart LM, Elliott MN, Lamb S, Uyeda KE, Hawes-Dawson J, et al: Increasing the availability and consumption of drinking water in middle schools: a pilot study. Prev Chronic Dis 2011;8:A60. http://www.cdc. gov/pcd/issues/2011/may/10_0105.htm. Accessed January 2015.
20 Ebbeling C, Feldman H, Chomitz V, Antonelli T, Gortmaker S, Osganian S, Ludwig DA: Randomized trial of sugar-sweetened beverages and adolescent body weight. N Engl J Med 2012;367:1407-1416.

-21 Visscher TLS, van Hal WCW, Blokdijk L, Seidell JC, Renders CM, Bemelmans WJE: Feasibility and impact of placing water coolers on sales of sugar-sweetened beverages in Dutch secondary school canteens. Obesity Facts 2010;3:109-115.

22 Tate DF, Turner-McGrievy G, Lyons E, Stevens J, Erickson K, Polzien K, Diamond M, Wang X, Popkin B: Replacing caloric beverages with water or diet beverages for weight loss in adults: main results of the Choose Healthy Options Consciously Everyday (CHOICE) randomized clinical trial. Am J Clin Nutr 2012;95:555-563.

23 Barquera S, Campos-Nonato I, HernandezBarrera L, Rivera Dommarco J: Encuesta Nacional de Salud y Nutricion 2012. Evidencia para la politica publica en salud. Obesidad en adultos: los retos de la cuesta abajo: Instituto Nacional de Salud Pública, 2012.

24 Hernández-Cordero S, González-Castell D, Rodríguez-Ramírez S, Villanueva-Borbolla MA, Unar M, Barquera S, González de Cossío T, Rivera-Dommarco J, Popkin B: Design and challenges of a randomized controlled trial for reducing risk factors of metabolic syndrome in Mexican women through water intake. Sal Pub Mexico 2013;55:595-606.

25 Hernández-Cordero S, Barquera S, Rodríguez-Ramírez S, Villanueva-Borbolla MA, González de Cossío T, Rivera-Dommarco J, Popkin B: Substituting water for sugar-sweetened beverages reduced circulating triglycerides and the prevalence of metabolic syndrome in obese but not in overweight Mexican women in a randomized controlled trial. J Nutr 2014;144:1742-1752.
Impact of Water Interventions and Sugar-Sweetened Beverages 